\title{
Insights and Perspectives on Sensory-Motor Integration and Rehabilitation
}

\author{
Rochelle Ackerley ${ }^{1,2}$, Michael Borich ${ }^{3}$, Calogero Maria Oddo ${ }^{4}$ \\ and Silvio Ionta ${ }^{5,6, *}$ \\ ${ }^{1}$ Department of Physiology, University of Gothenburg, Göteborg, Sweden \\ ${ }^{2}$ Laboratoire Neurosciences Intégratives et Adaptatives (UMR 7260), \\ CNRS - Aix-Marseille Université, Marseille, France \\ ${ }^{3}$ Neural Plasticity Research Laboratory, Division of Physical Therapy, Dept of Rehabilitation \\ Medicine, Emory University, Atlanta, GA, USA \\ ${ }^{4}$ The BioRobotics Institute, Scuola Superiore Sant'Anna, Pisa, Italy \\ ${ }^{5}$ The Laboratory for Investigative Neurophysiology, Dept of Radiology and Dept of Clinical \\ Neurosciences, University Hospital Center and University of Lausanne, Lausanne, Switzerland \\ ${ }^{6}$ Rehabilitation Engineering Laboratory, Department of Health Sciences and Technology, \\ ETH Zürich, Zurich, Switzerland
}

Received 2 November 2015; accepted 18 February 2016

\begin{abstract}
The present review focuses on the flow and interaction of somatosensory-motor signals in the central and peripheral nervous system. Specifically, where incoming sensory signals from the periphery are processed and interpreted to initiate behaviors, and how ongoing behaviors produce sensory consequences encoded and used to fine-tune subsequent actions. We describe the structure-function relations of this loop, how these relations can be modeled and aspects of somatosensory-motor rehabilitation. The work reviewed here shows that it is imperative to understand the fundamental mechanisms of the somatosensory-motor system to restore accurate motor abilities and appropriate somatosensory feedback. Knowledge of the salient neural mechanisms of sensory-motor integration has begun to generate innovative approaches to improve rehabilitation training following neurological impairments such as stroke. The present work supports the integration of basic science principles of sensory-motor integration into rehabilitation procedures to create new solutions for sensory-motor disorders.
\end{abstract}

\footnotetext{
* To whom correspondence should be addressed. E-mail: ionta.silvio@gmail.com 


\section{Keywords}

Biocomputational modeling, brain imaging, biomedical engineering, mechatronic tactile stimulators, artificial touch, neurorobotics

\section{Introduction}

Presently, we aim to unravel the nature and mechanisms responsible for the ability to organize sensory perceptions and motor routines, in order to open a window onto the organization of the somatosensory-motor loop. We will focus on somatosensory input and how this is processed and integrated centrally, to determine motor behavior. The fine balance between sensory input and motor output is essential for efficient interactions within the environment, and also includes the integration of incoming multisensory signals (e.g., vision, hearing, touch). Somatosensory feedback is pertinent for the fine tuning of dexterous movements. If this is impaired due to trauma or injury, due to, e.g., stroke or spinal cord injury, the incoming somatosensory signals are degraded and the effects can be very detrimental. In these cases, the absence of precise somatosensory feedback can render patients unable to perform movements despite the fact that basic motor function is relatively preserved (Ionta et al., 2016). In recent years, there have been important updates on the basic mechanisms, anatomo-functional neural basis, and rehabilitation procedures of such sensory-motor integration. Furthering the understanding of healthy and pathological somatosensory-motor integration mechanisms is essential and supports a theoretical model as general reference framework, with direct clinical outcomes.

In the next section we will provide a broad overview of state-of-the-art functional neuroimaging evidence on the interaction between somatosensory afferent information and efferent movement control, with a particular focus on touch. The third section will summarize the relationship between structural neuroimaging data and clinical phenotypes of sensory-motor disorders. In the fourth section we will discuss behavioral data within the framework of theoretical generalizations and modeling of the sensory-motor loop. The last section will discuss mechatronic tactile stimulation platforms developed in order to enable human touch studies with psychophysical and electrophysiological methods.

\section{Functional Bases of Somatosensory-Motor Processing}

The physiological investigation of the somatosensory system has its roots in pioneering studies of experimentalists such as Adrian, who investigated the afferent impulses from peripheral nerves (Adrian, 1926) and Penfield, who used electrical stimulation to map the sensorimotor cortex (Penfield and Boldrey, 
1937). Somatosensory-motor interactions are engrained in the fast conducting information that is sent to (afference) and from (efference) the central nervous system (Fourkas et al., 2006). The inherent accuracy and precision in this system allows us to engage in complex tasks, such as picking up a slippery object. It also provides a wealth of information for exploratory and manipulative tactile interactions with objects, allowing us to distinguish between multitudes of surfaces. Thus, for accurate motor control and exploration of the world, fast sensorimotor integration is essential. This is achieved through the comparison of motor behavior and its somatosensory consequences, with the inclusion of other factors, such as multisensory information (especially visual and auditory signals) and cognitive mechanisms, including experience, memory and learning.

Functional human brain imaging has provided us with a wealth of information about sensory and motor processes, and how these interact at a systems level. Nevertheless, we have much to learn about the normal functioning of these processes. One of the most immediate consequences of interacting physically with the environment is tactile perception. Concerning touch input, most studies have focused on afferent input to the primary somatosensory cortex (S1) to investigate how tactile information is processed; however, there are many other areas that contribute to decoding touch. The first stage in this process is the mechanoreception of interactions between the skin and external objects. Many different types of mechanoreceptive (touch) afferent contribute to somatosensation and the information transmitted depends on where the touch is received. The skin can be categorized by whether it is glabrous (nonhairy, e.g., the palms of the hands, soles of the feet) or hairy (the majority of the skin on the body). Different mechanoreceptive afferents are found at varying densities in the skin, which contribute to somatosensation by encoding various aspects of touch. The glabrous skin contains only fast conducting, myelinated mechanoreceptive afferents (see Fig. 1). These are densely packed in the glabrous skin and capable of encoding detailed aspects of touch, for example, pressure, force, vibration, edges, features and textures (Johnson, 2001). Additional types of fast conducting, myelinated afferents are found in hairy skin as well as slowly conducting, unmyelinated C-tactile (CT) afferents (Vallbo et al., 1993, 1995) (Fig. 1). Myelinated afferents are more sparsely found in the hairy skin, which contributes to its decreased tactile discrimination capabilities, as compared to the glabrous skin (Ackerley et al., 2014a; Weinstein, 1968). Thus the type of touch and where it is applied to the skin may result in different behaviors, depending on the afferents activated.

Once a tactile stimulus has been registered by these afferents, the information is sent to the spinal cord, before being relayed to $\mathrm{S} 1$, where tactile information is processed and integrated cortically (Mountcastle, 1957) (Fig. 1). This is the classical pathway for touch to reach the brain; however there are 


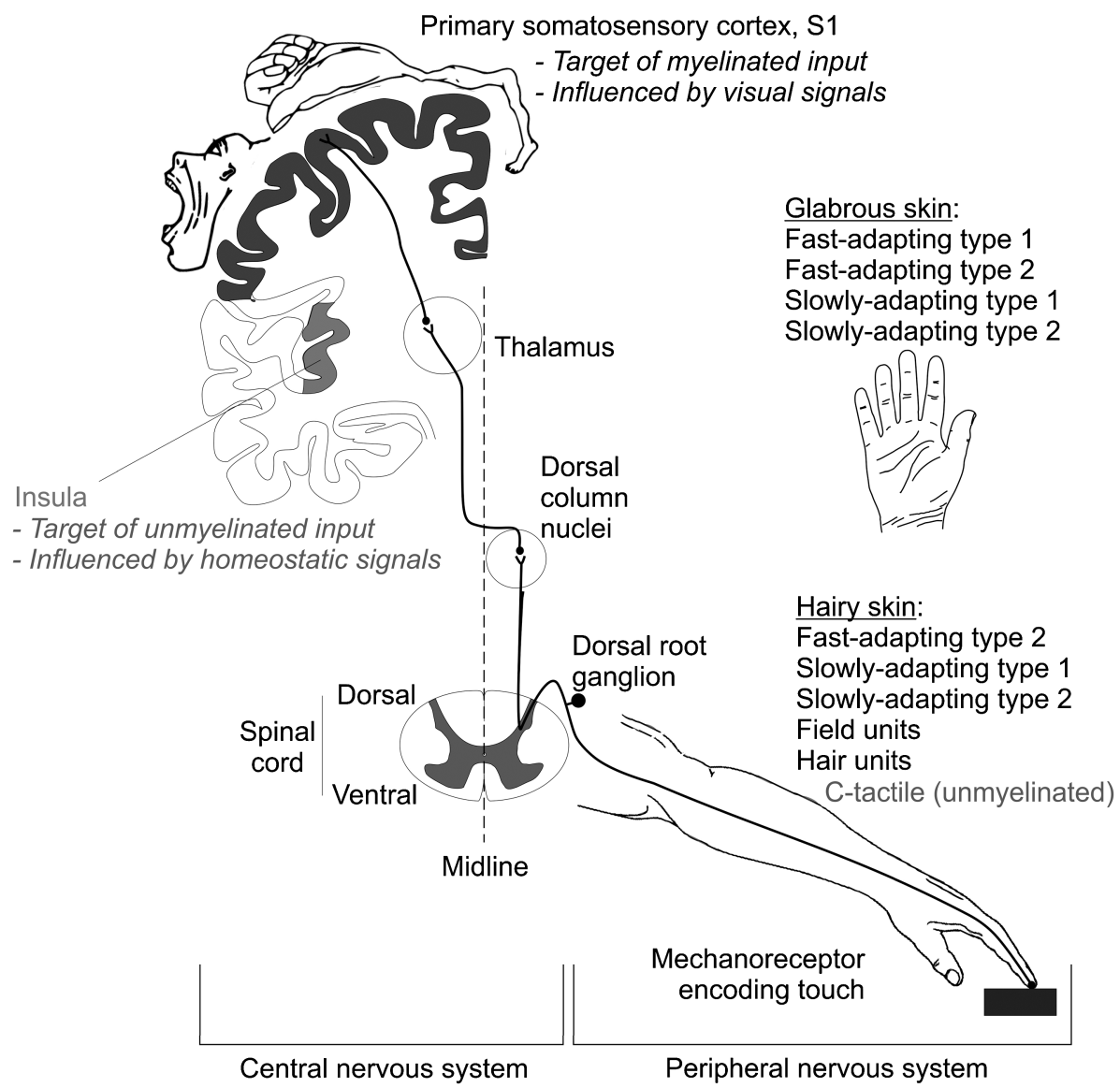

Figure 1. Overview of touch pathways from the periphery to brain. Once a tactile stimulus has been registered by mechanoreceptors in the skin, the information is sent to the primary somatosensory cortex (S1) or the insula, which are both somatosensory regions with different multisensory influences.

other ways that tactile information enters the brain (e.g., from CT afferents that project to the insula) and the processing of touch occurs over many different levels (Ackerley and Kavounoudias, 2015). The central target of touch information will in turn determine how the signals are processed, where the insula target is likely to be combined with much more emotional related information (e.g., with homeostatic mechanisms) and S1 with discriminative information (e.g., with vision) (Ackerley and Kavounoudias, 2015). The majority of mechanoreceptive research has focused on the touch from glabrous skin of the hands, due to its essential function in everyday life, which is exemplified in the amount of cortex dedicated to it, as seen by the proportionally greater representations in both the sensory and motor homunculi (Fig. 1). With 
advances in functional imaging technology, especially ultrahigh field (e.g., 7 Tesla, 7T) functional magnetic resonance imaging (fMRI), it is now possible to explore $\mathrm{S} 1$ in exquisite detail. Studies have shown precise intra- and interdigital representations in the subsections of S1 (i.e., Brodmann areas 3b, 1 and 2) (Martuzzi et al., 2014; Sanchez-Panchuelo et al., 2010, 2012; Stringer et al., 2011).

$\mathrm{S} 1$ is central to somatosensory-motor processing, as it receives the bulk of myelinated tactile information from the periphery, which is sent from the thalamus in a somatotopic fashion (homunculus), as found through the historic electrical mapping experiments of Penfield (Penfield and Boldrey, 1937; Rasmussen and Penfield, 1947). These pioneering experiments demonstrated that the human primary sensory and motor (M1) cortices show a distinct body map, where body parts with higher discriminative abilities are represented by larger cortical space and that the sensory and motor cortices are inexplicably linked in function. The precentral (motor) and postcentral (sensory) gyri both have these body map representations and they function together to aid in somatosensory integration. This was shown through electrical cortical stimulation, where S1 can produce movements and M1, sensation; hence these areas are not exclusively sensory and motor, respectively (Penfield and Boldrey, 1937). This is especially evident for the stimulation of the hand cortical areas, likely due to the large receptive fields dedicated to them and their importance in sensory-motor control. More recent studies have found further evidence for the close relationship between somatosensory and motor interactions, such as direct S1-M1 projections (Huerta and Pons, 1990), that S1 can drive exploratory protraction of the whiskers in mice (Matyas et al., 2010) and that the excitability of M1 is continuously modulated by somatosensory afference, especially during precise, fine motor control in humans (Tamburin et al., 2001).

The interplay between somatosensory and motor integration is highlighted in differences in the processing of active (self generated) and passive (other) touch. The similarity between active and passive touch is that near identical tactile afference may be generated provided that tactile stimulation platforms are properly tailored to the experimental framework (as discussed in Section 5); however, during active touch, motor commands (efference copy) are issued that can shape the meaning of the tactile feedback, as well as there being predictive mechanisms, such as through internal models (Wolpert et al., 1995). M1 plays a critical role in the execution of motor behavior and it has been postulated that tactile signals integrated into M1 may contribute to perception in active touch (Ferezou et al., 2007), for example, where the activity in M1 is modified by both the weight and texture of a grasped object (Picard and Smith, 1992). S1 is also modulated by active and passive touch (Ionta et al., 2014). A network of cortical areas, including the contralateral S1, bilat- 
eral secondary somatosensory cortex (S2) and posterior parietal cortex (PPC), is activated during all types of touch (Ackerley et al., 2012; Disbrow et al., 2000; Francis et al., 2000; Ruben et al., 2001). The contralateral M1 can also be activated during passive touch to the glabrous skin of the hands (Ackerley et al., 2012; Francis et al., 2000).

Active touch typically produces sensations that are less intense, as compared to passive touch (Ackerley et al., 2014b); however, this is not always the case, especially when the person seeks tactile information such as during the exploration of a surface for specific features. The classical idea of why you cannot tickle yourself (active self touch, compared to being tickled by another) captures the dynamic relationship between the processing of afference from self generated and other generated tactile signals (Blakemore et al., 1998, 2000; Weiskrantz et al., 1971). An efference copy signal from the motor intention cancels or countermands the incoming sensory consequence. Using fMRI, increased activity was found in S1 when the tickle was externally produced, thus there was a decreased signal during self tickle (Blakemore et al., 1998). The prediction of the sensory consequences of the self tickle meant that the incoming afference produced from self touch was gated out, thus less activity was seen in S1. On the other hand, increases in the signal in S1 during active touch, as compared to passive (other 'generated') touch, have been found in other tactile interactions, where attention is focused on the action and incoming afference (Ackerley et al., 2012; Simões-Franklin et al., 2011). Hence, it seems that there is a complex interaction between somatosensory and motor signals, with other cognitive factors such as attention and intention, which shape the way information is processed in S1.

Other cortical areas play key roles in processing and integrating somatosensory and motor information. S2 contributes to discriminative somatosensory processing, but does not contain the precise somatotopic body representations found in S1, rather the cortical receptive fields are large and overlapping for body areas, as found in monkey work (Fitzgerald et al., 2006; Sinclair and Burton, 1993; Thakur et al., 2006). Neurons in S2 have been found to code for more cognitive aspects of touch, including the stages of motor hand grasping, representations of past and present sensory information, modulations with attention, comparisons between stimuli, correlations with behavioral decisions, and discriminative learning (Hsiao et al., 2002; Ishida et al., 2013; Murray and Mishkin, 1984; Romo et al., 2002a, b). The cerebellum also has a major role in the integration of multisensory and motor signals, where there are dense projections from all over the cortex, including from somatosensory, motor, visual and emotional areas, to the cerebellum (Brodal, 1978; Leergaard and Bjaalie, 2007). Although it is particularly involved in integrating and finetuning somatosensory and motor information, it has the capacity for diverse 
information processing (Cerminara et al., 2015), where an internal model is constructed about the sensory-motor action (Wolpert et al., 1995).

The PPC and premotor cortex (PMC) are activated during haptic sensing, object recognition and sensorimotor transformations during visually guided motor activities, often providing a prehension signal to aid in processing sensory afference (Colby and Duhamel, 1996; Gardner et al., 2007), akin to the integrative role of the cerebellum. This suggests that these areas are key in the predictive and planning components of active touch, whereas S1 and M1 deal with the more immediate components of performance. The PMC in particular has been found to subserve motor and cognitive functions such as coordinating motor intentions and with the understanding of actions (Bonini et al., 2011; Rizzolatti et al., 2002). These two cortical areas have clear multimodal properties including motor, somatosensory and visual functions and contribute to transforming somatosensory information into motor behavior (Candidi et al., 2008). The influence of visual signals can also be found in somatosensorymotor processing. For example, coincident visual and tactile stimuli on human hands activates both the PMC and intraparietal sulcus for visuotactile integration (Gentile et al., 2011). Vision can modulate responses in S1, especially when the viewed stimulus implies tactile interactions or touch is observed (Meyer et al., 2011; Pihko et al., 2010). For instance, recent studies demonstrated the influence of vision over somatosensory processing in human-object and human-human interactions based on visuotactile integration (Ebisch et al., 2011; Ionta et al., 2013; Rossetti et al., 2012; Schaefer et al., 2009). These findings imply a more cognitive or emotional aspect to the modulation of somatosensory areas by visual signals.

Visuotactile interactions are pertinent in our everyday lives and the combination of incoming tactile and visual signals together with cognitive mechanisms such as memory, learning, attention, expectation and prediction, shape our behavior. The integration of human touch information is more dependent upon these higher level processes; however, it is postulated that positive affective tactile information is signaled directly by unmyelinated CT afferents that are only found in hairy skin and respond preferentially to gentle stroking touch (Ackerley et al., 2014c; Löken et al., 2009). These afferents encode pleasant social interactions at a basic level and send information to the insular cortex, known for its multisensory role in emotion and bodily regulation, as compared to the discriminative information sent to S1 (McGlone et al., 2014; Olausson et al., 2002). The multisensory experience of human touch, and its behavioral consequence, is therefore not just limited to tactile discrimination, but also includes visual, affective and emotional variables, such as pleasantness and arousal (Ackerley et al., 2014b), which affect the seeking or avoidance of somatosensory-motor interactions. For example, pleasant encounters will be 
interpreted as positive and be reinforced, whereas unpleasant situations will be dissuaded, aiding in the production of appropriate behavior.

\section{Structural Approaches to Study the Pathology of the Somatosensory-Motor Loop}

New advances in neuroimaging and neurostimulation approaches have begun to unravel the salient neural substrates underlying persisting motor dysfunction in a number of neurologic conditions (Borich et al., 2013b). A renewed interest has been placed on understanding and mapping the anatomical circuits that support neural function in the human brain. In this vein, recent work has evaluated the structural properties underlying multisensory mechanisms of somatosensory interactions (Brang et al., 2013; Van den Brink et al., 2014) demonstrating the importance of characterizing the anatomical substrates underlying multisensory function. For instance, a recent emphasis has been placed on studying the human brain connectome (Sporns et al., 2004) in an attempt to identify the underlying neuroanatomical connections in the brain that are necessary to understand the complex organization of local and distributed information processing. Currently, white matter imaging techniques (diffusion imaging, relaxometry, etc.) are the gold standard for noninvasively characterizing structural properties of brain networks. These new approaches can probe the brain architecture, providing insights on the effective integration of information across different sensory modalities to better shape motor outputs. From a rehabilitation and motor learning perspective, it has been shown that differences in brain structure after injury or in the context of neurologic disorders are associated with alterations in behavior (Avanzino et al., 2015). When combined with noninvasive brain stimulation (NIBS) approaches, structural imaging also offers exciting novel avenues to study brain structure-function relationships contributing to normal and abnormal sensorymotor function. The most common cause of adult disability is stroke and disability is largely due to disruption of the somatosensory motor loop resulting in motor dysfunction and decreased quality of life. Stroke provides a testable model to characterize the anatomical substrates of both normal and abnormal sensory-motor function and the potential for these substrates to be modified by experience. Additionally, in the rehabilitation literature, there has been a long term focus on stroke thus generating a large amount of knowledge regarding the underlying structural and functional correlates of disability and recovery. While there are clear differences in pathophysiology between stroke and other clinical populations, stroke provides a good model to study restorative and compensatory brain reorganization in response to relatively localized damage. Additionally, a large number of studies have demonstrated that the principles of experience-dependent neuroplastic change (which underlies mo- 
tor skill learning in healthy individuals) apply to the relearning of previously acquired motor skills or the acquisition of new motor skills in patients after stroke. Thus, focusing on stroke provides a reasonably well characterized model to study adaptive brain reorganization that supports restitution of function that is translatable into other clinical populations.

Using structural magnetic resonance imaging (sMRI) and diffusion weighted imaging (DWI), differences in gray and white matter structure have been demonstrated after stroke. These differences have the capacity to predict levels of sensory-motor dysfunction and response to rehabilitation in patients with stroke. In the context of neurologic disorders (e.g., Parkinson's disease) or after neurologic insult (e.g., stroke), the capacity for performing skilled movements is diminished. In the majority of cases, individuals do not regain previous levels of skill leading to persistent motor dysfunction and decreased quality of life (Edwards et al., 2010; Go et al., 2013). However, the capacity for learning new motor skills or relearning previous skills is rarely abolished. In both the context of heath and disease, motor skill learning is represented by structural and functional neuroplastic change in the brain. Neuroplastic change is constantly occurring and is influenced by a number of factors including characteristics of training (for review: Kleim and Jones, 2008) and processes associated with memory formation (Brashers-Krug et al., 1996; Ionta et al., 2010; Tononi and Cirelli, 2014). Brain imaging can provide a window into structural reorganization following neurologic insult but also into the mechanisms of adaptive plasticity associated with motor skill learning during rehabilitation. Using stroke as a model, the following sections will briefly summarize the current understanding of the influence of brain structure on long term prognosis, current motor performance and residual capacity for motor skill learning. Additionally, evidence for experience-dependent white matter plasticity will be discussed.

The human central nervous system consists of two fundamental types of tissue: gray matter and white matter. Most of the synapses and neurons in the brain are located in gray matter while the axons of neurons and supporting glial cells are primarily found in the white matter. The axons and glial cells are densely packed in white matter tracts that are responsible for information transmission within regions of the brain and between these regions and the rest of the body. One critical feature of white matter is myelin, an extension of glial cell membranes that wraps around axonal fibers to improve conduction velocity and reduce the energy requirements of axons (Van der Knaap and Valk, 2005). Due to the integral role of white matter and its structural organization, injuries in even small volumes of this tissue can have profoundly negative effects on multisensory integration underlying normal behavior.

A broad spectrum of neurologic disorders are associated with white matter pathology; specific examples include multiple sclerosis (MS), stroke, vascular 
dementia, schizophrenia and traumatic brain injury. In rodent models of both acute (Tanaka et al., 2003) and chronic (Chida et al., 2011) ischemic stroke, white matter degeneration is present. After stroke these changes lead to cognitive learning impairment and their reversal by remyelination is positively associated with cognitive recovery (Chida et al., 2011). In conjunction, recent work suggests that white matter may be an important therapeutic target to reduce the burden of disease associated with certain neurologic disorders (for review: Dobkin, 2007; Stys and Lipton, 2008).

Unique and detailed information about white matter anatomy and brain recovery following stroke can be generated using diffusion weighted imaging (DWI). DWI capitalizes on the diffusive properties of water to determine microstructural integrity of white matter. Fractional anisotropy (FA) is a quantitative, unitless measure of diffusion behavior of water in the brain. It is influenced by microstructural properties of white matter and is the most commonly reported measure of white matter integrity after stroke (Jang, 2010). After stroke, white matter tract integrity can be affected both locally and distally to the primary lesion location (Werring et al., 2000). Abnormal white matter tissue microstructural properties in ipsi- or contralesional descending motor output pathways have been associated with greater levels of physical impairment and motor dysfunction (Borich et al., 2012; Qiu et al., 2011; Stinear et al., 2007), reduced motor learning (Borich et al., 2013a; Stinear et al., 2007), and hand sensory-motor dysfunction (Borich et al., 2012; Borstad et al., 2012; Schaechter et al., 2009). Mean FA values in descending motor output pathways measured acutely after stroke have also been used as part of an algorithm used to predict potential for functional recovery (Stinear et al., 2012).

There is substantial evidence demonstrating positive neuroplastic change after stroke (Boyd and Winstein, 2003; Taub et al., 1993). It has been clearly shown that capacity for neuroplastic change is preserved, even in individuals with chronic stroke (as demonstrated by fMRI and improvements in motor function - Boyd and Winstein, 2003, 2004a, b, 2006; Boyd et al., 2009; Pohl and Winstein, 1999; Velicki et al., 2000; Vidoni and Boyd, 2009; Winstein et al., 1999) (Boyd et al., 2007; Meehan et al., 2011). Although increasing the amount of skilled use of the paretic side induces neuroplastic change in gray matter (Calautti and Baron, 2003; Calautti et al., 2001a, b, 2004; Sawaki, et $a l ., 2008$ ), the dose of movement required is exceedingly high (Lang et al., 2009). Currently, definitive numbers of repetitions needed for optimal learning (Kleim and Jones, 2008) to stimulate neuroplastic change in gray (Luke et al., 2004) or white matter (Scholz et al., 2009) are unknown. What is known is that low doses of task-specific movement practice occur during stroke rehabilitation (Lang et al., 2007, 2009) that are likely suboptimal for inducing lasting structural and functional neuroplastic change to improve sensory-motor net- 
work activity underlying behavior. Thus, alternative approaches have been pursued to augment experience-dependent neuroplasticity after stroke.

Following stroke, NIBS may be used to re-establish the altered balance of cortical excitability between the hemispheres (Murase et al., 2004; Shimizu et $a l ., 2004)$ and/or pre-excite a cortical region that will be engaged in subsequent behavioral practice (Boyd and Linsdell, 2009). Yet, on average, the reported effects of NIBS in individuals with stroke are small (Bell et al., 2008) and varied (Brodie et al., 2014; Carey et al., 2014). Since the first clinical trial of repetitive transcranial magnetic stimulation (rTMS), a common form of NIBS in 2001, a substantial number of investigations have been conducted to evaluate the therapeutic potential of rTMS to modulate cortical activity and improve function after stroke (Lefaucheur et al., 2014). However, due to a number of factors including small sample sizes, heterogeneity of participant characteristics, undefined optimal stimulation parameters and lack of synergistic skill training applications, the positive effects of rTMS on sensory-motor function in stroke have been modest (Hao et al., 2013; Le et al., 2014; Lefaucheur et al., 2014).

Combining structural imaging approaches with NIBS offers opportunities to probe the structure-function relationships contributing to abnormal sensory-motor function and response to NIBS-based interventions. For example, it was shown recently that response to an intervention pairing rTMS over the ipsilesional S1 prior to motor skill training using the paretic arm was predicted by the volume of white matter within ipsilesional S1 as measured by sMRI prior to beginning the intervention (Brodie et al., 2014). This example highlights potential applications of structural imaging approaches to identify potential biomarkers of response to NIBS paradigms to better tailor novel therapeutic interventions to the characteristics of a given individual. Longitudinal imaging assessments of brain structure can capture aspects of anatomical reorganization during stroke recovery but can also be used to monitor neuroplastic change associated with rehabilitation to determine if sufficient experiencedependent plasticity in brain regions involved in multisensory integration is being driven by a given intervention.

For stroke rehabilitation approaches to be maximally effective on a patientby-patient basis, it is critical to address all sensory systems involved in each functional task of interest. Although incorporating multiple sensory systems during rehabilitation is commonly understood in contemporary treatment approaches, limited research has directly focused on multisensory approaches in a stroke rehabilitation context. Recently a review of multisensory stimulation was published showing positive benefits of concomitantly stimulating multiple sensory areas to improve sensory function after stroke (Tinga et al., 2016). However, a quantitative quality assessment suggested that definitive conclusions could not be reached due to methodological issues of the studies 
included in the review. Additionally, the multisensory stimulation interventions were focused on sensory function rather than the way a given intervention directly impacts the restoration of motor function. Recently, a pilot study demonstrated the feasibility of a virtual reality-based approach utilizing multisensory feedback during movement to improve motor function (Kato et al., 2015). Although encouraging, the pilot nature of this investigation precludes definitive conclusions regarding the benefits of multisensory approaches in stroke rehabilitation. Although historically not a specific focus of rehabilitation research, it is commonly understood that a multisensory approach is beneficial to stroke rehabilitation but future research to evaluate the degree of benefit of these approaches compared to unisensory approaches would further substantiate current clinical practice.

In the context of motor learning, there are clear advantages of taking a multisensory approach to improve recovery after stroke. During stroke rehabilitation, the recovery of function requires the same memory formation processes underlying motor learning in healthy individuals. Under typical conditions, these motor skill memories are formed using multisensory information from the external and internal environments. For example, recovery of functional paretic arm reach to grasp activities requires processing of multisensory information from the somatosensory system, proprioceptive system and visual system. The advantage of taking a multisensory approach to understand stroke and stroke recovery is that this approach accounts for the role of each sensory system in performing and (re) learning functional movements. Without accounting for one or all of the sensory systems involved in a skilled task during stroke rehabilitation will result in a suboptimal approach to motor skill learning underlying the recovery of function.

\section{Modeling Sensory-Motor Integration}

Conceiving theoretical models to explain the causal link between dysfunctional brain networks and clinical phenotypes is a major challenge in cognitive neuroscience. In the current models of sensory-motor integration the reciprocal role of somatosensory and motor mechanisms is still unclear. Here we will enclose the reviewed evidence on typical and pathological sensorymotor organization in a general theoretical model of modes and operations of sensory-motor processing.

Classic models of sensory-motor integration postulate that the process as a whole can be broken down into different subaspects (nodes) and that the activity of specific spatiotemporally specialized neural substrates can be attributed to each individual aspect, or node (Sanger and Merzenich, 2000; Shadmehr and Krakauer, 2008; Wolpert et al., 1995). Recent theorizations of sensorymotor integration propose that the first activated nodes encode the movement 
preparation phase, preloading the sequence of single movements required to perform an action (Borich et al., 2015). Converging evidence supports that after the intention to move, this movement planning phase is encoded by activity in premotor and supplementary motor regions (e.g., Ionta et al., 2010). Then the signal is translated into a motor command and a replication of the command itself (efference copy) is used to predict the expected motor outcome (forward model) (Von Holst and Mittelstaedt, 1950). Simultaneously, the efference copy is combined with the information about the current body state and entered in a feedforward prediction model (Adams et al., 2013; Wolpert et al., 1998). First, the feedforward model anticipates the somatosensory consequences of the motor command (Blakemore et al., 2000), improving monitoring and error detection. Second, the outcome of the comparison between the expected and the actual somatosensory inflow is volleyed back to the structures encoding the translation of motor planning into motor command, closing the sensory-motor loop (Perruchoud et al., 2014).

At the neural level, the premotor (Desmurget et al., 2009) and supplementary motor regions (Ionta et al., 2010) encode the movement preparation phase. Then the signal is transferred to the motor command node (M1) to trigger the movement (Tanji et al., 1996). Not only does M1 send the signal to the corticospinal tract, but it also generates a copy of the signal (the efference copy) to be entered into the forward model in the parietal cortex (Wolpert et al., 1998). At the same time, the forward model enters information about the estimated movement outcome into the feedforward model, primarily involving the cerebellum (Blakemore et al., 2000). The real somatosensory inflow is first encoded and then compared with the anticipated somatosensory prediction by the activity of basal ganglia, thalamus, and cerebellum (Schlerf et al., 2012). Then the result of this comparison is sent to $\mathrm{S} 1$, and premotor and supplementary motor regions (Busan et al., 2009). Based on the acquired information on the current and the estimated body state, S1 (Borich et al., 2015), premotor (Sun et al., 2015) and supplementary motor (Carlsen et al., 2015) regions then project back to M1, in order to calibrate the resulting movement and close the sensory-motor loop (Perruchoud et al., 2014).

Clinically, it can be hypothesized that when afferent somatosensory information is not available (as after complete spinal cord injury), the somatosensory encoding nodes of the sensory-motor loop cannot receive information on the current state and therefore have to rely uniquely on the forward prediction model, causing a general and unsolvable instability of the whole system. This unreliability can trigger a change in the relative weight of kinesthetic and visuospatial body representations. In other words, in pathological conditions affecting the acquirement of the information required to correctly represent the body, we are able to switch strategy in order to use a different reference frame (e.g., visuospatial) and accommodate ecologically appropriate adaptations, 
e.g., visually guided movements (Rothwell et al., 1982). This interpretation is in line with the evidence suggesting that movement representations are largely multimodal (Halje et al., 2015) and that the interplay between these different representations can change in the case of missing (Curtze et al., 2010), disconnected (Fiori et al., 2014) or misrepresented limbs (Daprati et al., 2010).

\section{How to Deliver the Stimulus? Neuro-Robotic Tools to Investigate the Somatosensory System and to Evaluate Artificial Tactile Sensors for Neuroprostheses}

The loop between neuroscientific research and biomedical engineering is of major importance for rehabilitation (Pisotta et al., 2015). Neurophysiological studies on the somatosensory system require the precise, repeatable, and unobtrusive delivery of tactile stimuli in controlled situations. This is typically achieved by means of passive touch experimental methods (see Section 2 for illustration of active versus passive touch frameworks). In passive touch experiments, the planning and execution of the task underlying the stimulation is external to the subject and hence no voluntary action is required and no efference copy is generated, which has consequences on the brain areas and processes involved (see Section 4 for discussion). The exploration of these sensorimotor relationships is enabled by the development of tools such as mechatronic tactile stimulators suitable for electrophysiological recordings and behavioral studies with psychophysical methods. Several of such platforms have been presented in the literature, with different constructive choices depending on the investigated somatosensory modality (e.g., mechanical, thermal), on the possible combination with the activation of other senses (e.g., vision, audition), on the targeted experimental protocol (e.g., adaptive staircase methods) and experimental environment (e.g., suitable for being applied in combination with microneurography, EEG or MRI studies). In this vein, touch may be a channel for multisensory substitution. This is the case of stimulators with pinned elements, that allow applying both local forces and generalized textures via traveling spatiotemporal mechanical waves, and that are used as touch-based assistive devices for visually impaired as well as in neuroscientific investigations (Bliss et al., 1970; Gardner and Palmer, 1989; Hayward et al., 2014; Killebrew et al., 2007; Kyung et al., 2006; Summers and Chanter, 2002; Vidal-Verdú and Hafez, 2007). Tactile stimulation is also used in combination with audio (Ghali et al., 2012) or visual (Lunghi and Morrone, 2013) stimulation to study multisensory integration or to promote an immersive virtual reality experience that was investigated in some cases under magnetic resonance imaging (Duenas et al., 2011; Ku et al., 2003).

Even within one sensory modality, it is crucial to consider all the different aspects that are processed and combined by similar neural mechanisms. For 
instance, considering somatosensations, some tactile stimulators can deliver to the skin either simple pressure and displacement (Birznieks et al., 2001; Byrne, 1975; Looft and Williams, 1979; Nakazawa et al., 2000; Pawluk and Howe, 1999; Romo et al., 1993; Wheat et al., 2004) or complex texture surfaces (Darian-Smith and Oke, 1980; Goodwin et al., 1985; Johnson and Lamb, 1981; Johnson and Phillips, 1988; LaMotte et al., 1983; Oddo et al., 2011a; Tomassini et al., 2011; Weber et al., 2013; Wiertlewski et al., 2011). However somatosensation is not limited to these features. Indeed, some novel systems also integrate temperature regulation (Bruce, 1982) and, in combination with mechanical stimulation, can be used to investigate multimodal sensory integration, e.g., between temperature and force (Ackerley et al., 2014c; Davis et al., 1998; Klöcker et al., 2014). Such multimodal studies address the investigation of how both mechanical and thermal features of tactile stimuli contribute to the perception of their pleasantness level, hence linking the discriminative and affective components of touch experience. In some devices particular engineering solutions (e.g., shielding techniques, pneumatic actuation and cable driven transmission among several approaches) were introduced in order to allow the delivery of thermal (Davis et al., 1998) or mechanical (Dykes et al., 2007; Golaszewski et al., 2006) stimuli to be compatible with MRI studies, whereas the tactile stimulus delivery was not under automatic control and manual application of calibrated filaments was used (Schaechter et al., 2006) in MRI studies not requiring the dynamic change of stimulation parameters (see Section 3 for discussion with a particular focus on stroke).

In conclusion, the tight integration between robotics and neuroscience enables progression both in the understanding of the somatosensory system (Johansson and Flanagan, 2009; Jörntell et al., 2014) and towards translational neuroprosthetic applications (Saal and Bensmaia, 2015). As a matter of fact, robotics allows closing the loop between sensory and motor domains, especially in cases where physical elements of the body are missing or disconnected, e.g., amputation or spinal cord injury (Pisotta et al., 2015). Also, thanks to these synergies between disciplines, the same experimental platforms and methods applied in neuroscientific research can also be used for the characterization of artificial tactile sensors (Edwards et al., 2008; Fishel and Loeb, 2012; Fishel et al., 2008; Kim et al., 2013; Oddo et al., 2011b; Rongala et al., 2015; Scheibert et al., 2009). According to such synergistic approaches, the same physical stimuli used in human touch studies can be applied for the evaluation of robotic tactile sensors, with similar stimulation conditions such as contact force (typical ranges between tens of $\mathrm{mN}$ up to several $\mathrm{N}$ ) and motion dynamics at stimulus-sensor interface (from few $\mathrm{mm} / \mathrm{s} \mathrm{up}$ to hundreds of $\mathrm{mm} / \mathrm{s}$ of tangential velocity). In robotic experiments inspired by neuroscientific protocols, the human perceptual thresholds estimated via psychophysical methods are used as a benchmarking reference for the results 
achieved via machine learning on sensor data. This approach allows establishing fertile understanding-generation loops prior to porting the artificial touch technology to the afferent pathways of amputees by means of bionic limb prostheses (Dhillon and Horch, 2005; Oddo et al., 2016; Ortiz-Catalan et al., 2014; Raspopovic et al., 2014; Tan et al., 2014).

\section{Acknowledgements}

This work was supported by the Swiss National Science Foundation through the Ambizione funding program to Silvio Ionta (grant PZ00P1_148186), and by the Italian Ministry for Education, Universities and Research through the PRIN HandBot project to Calogero Maria Oddo (grant CUP B81J12002680008).

\section{References}

Ackerley, R. and Kavounoudias, A. (2015). The role of tactile afference in shaping motor behaviour and implications for prosthetic innovation, Neuropsychologia 79B, 192-205.

Ackerley, R., Hassan, E., Curran, A., Wessberg, J., Olausson, H. and McGlone, F. (2012). An fMRI study on cortical responses during active self-touch and passive touch from others, Front. Behav. Neurosci. 6, 51.

Ackerley, R., Carlsson, I., Wester, H., Olausson, H. and Backlund Wasling, H. (2014a). Touch perceptions across skin sites: differences between sensitivity, direction discrimination and pleasantness, Front. Behav. Neurosci. 8, 54. DOI:10.3389/fnbeh.2014.00054.

Ackerley, R., Saar, K., McGlone, F. and Backlund Wasling, H. (2014b). Quantifying the sensory and emotional perception of touch: differences between glabrous and hairy skin, Front. Behav. Neurosci. 8, 34. DOI:10.3389/fnbeh.2014.00034.

Ackerley, R., Backlund Wasling, H., Liljencrantz, J., Olausson, H., Johnson, R. D. and Wessberg, J. (2014c). Human C-tactile afferents are tuned to the temperature of a skin-stroking caress, J. Neurosci. 34, 2879-2883.

Adams, R. A., Shipp, S. and Friston, K. J. (2013). Predictions not commands: active inference in the motor system, Brain Struct. Funct. 218, 611-643.

Adrian, E. (1926). The impulses produced by sensory nerve endings. Part I, J. Physiol. 61, 49-72.

Avanzino, L., Tinazzi, M., Ionta, S. and Fiorio, M. (2015). Sensory-motor integration in focal dystonia, Neuropsychologia 79B, 288-300.

Bell, C. J., Shenoy, P., Chalodhorn, R. and Rao, R. P. (2008). Control of a humanoid robot by a noninvasive brain-computer interface in humans, J. Neural Eng. 5, 214-220.

Birznieks, I., Jenmalm, P., Goodwin, A. W. and Johansson, R. S. (2001). Encoding of direction of fingertip forces by human tactile afferents, J. Neurosci. 21, 8222-8237.

Blakemore, S. J., Wolpert, D. M. and Frith, C. D. (1998). Central cancellation of self-produced tickle sensation, Nat. Neurosci. 1, 635-640.

Blakemore, S. J., Wolpert, D. and Frith, C. (2000). Why can't you tickle yourself? Neuroreport 11, R11-R16. 
Bliss, J. C., Katcher, M. H., Rogers, C. H. and Shepard, R. P. (1970). Optical-to-tactile image conversion for the blind, IEEE Trans. Man-Machine Syst. 11, 58-65.

Bonini, L., Serventi, F. U., Simone, L., Rozzi, S., Ferrari, P. F. and Fogassi, L. (2011). Grasping neurons of monkey parietal and premotor cortices encode action goals at distinct levels of abstraction during complex action sequences, J. Neurosci. 31, 5876-5886.

Borich, M. R., Mang, C. and Boyd, L. A. (2012). Both projection and commissural pathways are disrupted in individuals with chronic stroke: investigating microstructural white matter correlates of motor recovery, BMC Neurosci. 13, 107.

Borich, M. R., Brown, K. E. and Boyd, L. A. (2013a). Motor skill learning is associated with diffusion characteristics of white matter in individuals with chronic stroke, J. Neurol. Phys. Ther. 38, 151-160.

Borich, M. R., MacKay, A. L., Vavasour, I. M., Rauscher, A. and Boyd, L. A. (2013b). Evaluation of white matter myelin water fraction in chronic stroke, NeuroImage Clin. 2, 569-580.

Borich, M. R., Brodie, S. M., Gray, W. A., Ionta, S. and Boyd, L. A. (2015). Understanding the role of the primary somatosensory cortex: opportunities for rehabilitation, Neuropsychologia 79B, 246-255.

Borstad, A., Schmalbrock, P., Choi, S. and Nichols-Larsen, D. S. (2012). Neural correlates supporting sensory discrimination after left hemisphere stroke, Brain Res. 1460, 78-87.

Boyd, L. A. and Linsdell, M. A. (2009). Excitatory repetitive transcranial magnetic stimulation to left dorsal premotor cortex enhances motor consolidation of new skills, BMC Neurosci. 10, 72 .

Boyd, L. A. and Winstein, C. J. (2003). Impact of explicit information on implicit motorsequence learning following middle cerebral artery stroke, Phys. Ther. 83, 976-989.

Boyd, L. A. and Winstein, C. J. (2004a). Cerebellar stroke impairs temporal but not spatial accuracy during implicit motor learning, Neurorehabil. Neural Repair 18, 134-143.

Boyd, L. A. and Winstein, C. J. (2004b). Providing explicit information disrupts implicit motor learning after basal ganglia stroke, Learn. Mem. 11, 388-396.

Boyd, L. and Winstein, C. (2006). Explicit information interferes with implicit motor learning of both continuous and discrete movement tasks after stroke, J. Neurol. Phys. Ther. 30, 4657; discussion 58-59.

Boyd, L. A., Vidoni, E. D. and Daly, J. J. (2007). Answering the call: the influence of neuroimaging and electrophysiological evidence on rehabilitation, Phys. Ther. 87, 684-703.

Boyd, L. A., Edwards, J. D., Siengsukon, C. S., Vidoni, E. D., Wessel, B. D. and Linsdell, M. A. (2009). Motor sequence chunking is impaired by basal ganglia stroke, Neurobiol. Learn. Mem. 92, 35-44.

Brang, D., Taich, Z. J., Hillyard, S. A., Grabowecky, M. and Ramachandran, V. S. (2013). Parietal connectivity mediates multisensory facilitation, Neuroimage 78, 396-401.

Brashers-Krug, T., Shadmehr, R. and Bizzi, E. (1996). Consolidation in human motor memory, Nature 382(6588), 252-255.

Brodal, P. (1978). The corticopontine projection in the rhesus monkey. Origin and principles of organization, Brain 101, 251-283.

Brodie, S. M., Borich, M. R. and Boyd, L. A. (2014). Impact of 5-Hz rTMS over the primary sensory cortex is related to white matter volume in individuals with chronic stroke, Eur. $J$. Neurosci. 9, 3405-3412.

Bruce, M. F. (1982). A simple apparatus to assess cutaneous thermal sensitivity, J. Neurol. Neurosurg. Psychiat. 45, 557-559. 
Busan, P., Barbera, C., Semenic, M., Monti, F., Pizzolato, G., Pelamatti, G. and Battaglini, P. P. (2009). Effect of transcranial magnetic stimulation (TMS) on parietal and premotor cortex during planning of reaching movements, PLOS ONE 4, e4621.

Byrne, J. (1975). A feedback controlled stimulator that delivers con-trolled displacements or forces to cutaneous mechanoreceptors, IEEE Trans. Biomed. Eng. 22, 66-69.

Calautti, C. and Baron, J. C. (2003). Functional neuroimaging studies of motor recovery after stroke in adults - a review, Stroke 34, 1553-1566.

Calautti, C., Guincestre, J. Y., Leroy, F., Marie, R. M. and Baron, J. C. (2001a). Neuronal correlates of objective motor recovery after subcortical stroke: a prospective and longitudinal PET activation study, Neuroimage 13, S1142-S1142.

Calautti, C., Leroy, F., Guincestre, J. Y. and Baron, J. C. (2001b). Dynamics of motor network overactivation after striatocapsular stroke - a longitudinal PET study using a fixedperformance paradigm, Stroke 32, 2534-2542.

Calautti, C., Naccarato, M., Jones, P. S., Day, D. J., Fletcher, P. C., Carpenter, T. A., Bullmore, E. T., Warburton, E. A. and Baron, J. C. (2004). Motor performance in the stable phase of recovery after subcortical stroke is related to laterality of motor network activation, Stroke 35, 285.

Candidi, M., Urgesi, C., Ionta, S. and Aglioti, S. M. (2008). Virtual lesion of ventral premotor cortex impairs visual perception of biomechanically possible but not impossible actions, Soc. Neurosci. 3, 388-400.

Carey, J. R., Deng, H., Gillick, B. T., Cassidy, J. M., Anderson, D. C., Zhang, L. and Thomas, W. (2014). Serial treatments of primed low-frequency rTMS in stroke: characteristics of responders vs. nonresponders, Restor. Neurol. Neurosci. 32, 323-335.

Carlsen, A. N., Eagles, J. S. and MacKinnon, C. D. (2015). Transcranial direct current stimulation over the supplementary motor area modulates the preparatory activation level in the human motor system, Behav. Brain Res. 279, 68-75.

Cerminara, N. L., Lang, E. J., Sillitoe, R. V. and Apps, R. (2015). Redefining the cerebellar cortex as an assembly of non-uniform Purkinje cell microcircuits, Nat. Rev. Neurosci. 16, 79-93.

Chida, Y., Kokubo, Y., Sato, S., Kuge, A., Takemura, S., Kondo, R. and Kayama, T. (2011). The alterations of oligodendrocyte, myelin in corpus callosum, and cognitive dysfunction following chronic cerebral ischemia in rats, Brain Res. 1414, 22-31.

Colby, C. L. and Duhamel, J. R. (1996). Spatial representations for action in parietal cortex, Brain Res. Cogn. Brain Res. 5, 105-115.

Curtze, C., Otten, B. and Postema, K. (2010). Effects of lower limb amputation on the mental rotation of feet, Exp. Brain Res. 201, 527-534.

Daprati, E., Nico, D., Duval, S. and Lacquaniti, F. (2010). Different motor imagery modes following brain damage, Cortex 46, 1016-1030.

Darian-Smith, I. and Oke, L. E. (1980). Peripheral neural representation of the spatial frequency of a grating moving across the monkey's finger pad, J. Physiol. 309, 117-133.

Davis, K. D., Kwan, C. L., Crawley, A. P. and Mikulis, D. J. (1998). Functional MRI study of thalamic and cortical activations evoked by cutaneous heat, cold, and tactile stimuli, J. Neurophysiol. 80, 1533-1546.

Desmurget, M., Reilly, K. T., Richard, N., Szathmari, A., Mottolese, C. and Sirigu, A. (2009). Movement intention after parietal cortex stimulation in humans, Science 324, 811-813. 
Dhillon, G. S. and Horch, K. W. (2005). Direct neural sensory feedback and control of a prosthetic arm, IEEE Trans. Neural Syst. Rehabil. Eng. 13, 468-472.

Disbrow, E., Roberts, T. and Krubitzer, L. (2000). Somatotopic organization of cortical fields in the lateral sulcus of Homo sapiens: evidence for SII and PV, J. Comp. Neurol. 418, 1-21.

Dobkin, B. H. (2007). Behavioral, temporal, and spatial targets for cellular transplants as adjuncts to rehabilitation for stroke, Stroke 38, 832-839.

Duenas, J., Chapuis, D., Pfeiffer, C., Martuzzi, R., Ionta, S., Blanke, O. and Gassert, R. (2011). Neuroscience robotics to investigate multisensory integration and bodily awareness, in: Engineering in Medicine and Biology Society, EMBC, 2011 Annual International Conference of the IEEE, pp. 8348-8352.

Dykes, R. W., Miqueé, A., Xerri, C., Rainville, C., Dumoulin, A. and Marineau, D. (2007). A delivery device for presentation of tactile stimuli during functional magnetic resonance imaging, J. Neurosci. Meth. 159, 308-317.

Ebisch, S. J. H., Ferri, F., Salone, A., Perrucci, M. G., D’Amico, L., Ferro, F. M., Romanim, G. L. and Gallese, V. (2011). Differential involvement of somatosensory and interoceptive cortices during the observation of affective touch, J. Cogn. Neurosci. 23, 1808-1822.

Edwards, J., Lawry, J., Rossiter, J. and Melhuish, C. (2008). Extracting textural features from tactile sensors, Bioinspir. Biomim. 3, 035002. DOI:10.1088/1748-3182/3/3/035002.

Edwards, J. D., Koehoorn, M., Boyd, L. A. and Levy, A. L. (2010). Is health-related quality of life improving after stroke? A comparison of health utilities indices among canadians with stroke between 1996 and 2005, Stroke 42, 996-1000.

Ferezou, I., Haiss, F., Gentet, L. J., Aronoff, R., Weber, B. and Petersen, C. C. (2007). Spatiotemporal dynamics of cortical sensorimotor integration in behaving mice, Neuron 56, 907-923.

Fiori, F., Sedda, A., Ferre, E. R., Toraldo, A., Querzola, M., Pasotti, F., Ovadia, D., Piroddi, C., Dell'Aquila, R., Redaelli, T. and Bottini, G. (2014). Motor imagery in spinal cord injury patients: moving makes the difference, J. Neuropsychol. 8, 199-215.

Fishel, J. A. and Loeb, G. E. (2012). Bayesian exploration for intelligent identification of textures, Front. Neurorobot. 6, 1-20.

Fishel, J. A., Santos, V. J. and Loeb, G. E. (2008). A robust micro-vibration sensor for biomimetic fingertips, in: BioRob 2008. 2nd IEEE RAS and EMBS International Conference on Biomedical Robotics and Biomechatronics, pp. 659-663.

Fitzgerald, P. J., Lane, J. W., Thakur, P. H. and Hsiao, S. S. (2006). Receptive field properties of the macaque second somatosensory cortex: representation of orientation on different finger pads, J. Neurosci. 26, 6473-6484.

Fourkas, A. D., Ionta, S. and Aglioti, S. M. (2006). Influence of imagined posture and imagery modality on corticospinal excitability, Behav. Brain Res. 168, 190-196.

Francis, S. T., Kelly, E. F., Bowtell, R., Dunseath, W. J., Folger, S. E. and McGlone, F. (2000). fMRI of the responses to vibratory stimulation of digit tips, Neuroimage 11, 188-202.

Gardner, E. P. and Palmer, C. I. (1989). Simulation of motion on the skin: I. Receptive fields and temporal frequency coding by cutaneous mechanoreceptors of OPTACON pulses delivered to the hand, J. Neurophysiol. 62, 1410-1436.

Gardner, E. P., Ro, J. Y., Babu, K. S. and Ghosh, S. (2007). Neurophysiology of prehension. II. Response diversity in primary somatosensory (S-I) and motor (M-I) cortices, J. Neurophysiol. 97, 1656-1670. 
Gentile, G., Petkova, V. I. and Ehrsson, H. H. (2011). Integration of visual and tactile signals from the hand in the human brain: an FMRI study, J. Neurophysiol. 105, 910-922.

Ghali, N. I., Soluiman, O., El-Bendary, N., Nassef, T. M., Ahmed, S. A., Elbarawy, Y. M. and Hassanien, A. E. (2012). Virtual reality technology for blind and visual impaired people: reviews and recent advances, in: Advances in Robotics and Virtual Reality, T. Gulrez and A. E. Hassanien (Eds), pp. 363-385. Springer, Berlin, Germany.

Go, A. S., Mozaffarian, D., Roger, V. L., Benjamin, E. J., Berry, J. D., Borden, W. B., Bravata, D. M., Dai, S., Ford, E. S., Fox, C. S., Franco, S., Fullerton, H. J., Gillespie, C., Hailpern, S. M., Heit, J. A., Howard, V. J., Huffman, M. D., Kissela, B. M., Kittner, S. J., Lackland, D. T., Lichtman, J. H., Lisabeth, L. D., Magid, D., Marcus, G. M., Marelli, A., Matchar, D. B., McGuire, D. K., Mohler, E. R., Moy, C. S., Mussolino, M. E., Nichol, G., Paynter, N. P., Schreiner, P. J., Sorlie, P. D., Stein, J., Turan, T. N., Virani, S. S., Wong, N. D., Woo, D. and Turner, M. B. (2013). Heart disease and stroke statistics-2013 update: a report from the American Heart Association, Circulation 127, e6-e245.

Golaszewski, S. M., Siedentopf, C. M., Koppelstaetter, F., Fend, M., Ischebeck, A., GonzalezFelipe, V., Haala, I., Struhal, W., Mottaghy, F. M. and Gallasch, E. (2006). Human brain structures related to plantar vibrotactile stimulation: a functional magnetic resonance imaging study, Neuroimage 29, 923-929.

Goodwin, A., Morley, J., Clarke, C., Lumaksana, B. and Darian-Smith, I. (1985). A stimulator for moving textured surfaces sinusoidally across the skin, J. Neurosci. Meth. 14, 121-125.

Halje, P., Seeck, M., Blanke, O. and Ionta, S. (2015). Inferior frontal oscillations reveal visuomotor matching for actions and speech: evidence from human intracranial recordings, $\mathrm{Neu}$ ropsychologia 79B, 206-214.

Hao, Z., Wang, D., Zeng, Y. and Liu, M. (2013). Repetitive transcranial magnetic stimulation for improving function after stroke, Cochrane Database Syst. Rev. 5, CD008862. DOI:10.1002/14651858.CD008862.pub2.

Hayward, V., Terekhov, A. V., Wong, S.-C., Geborek, P., Bengtsson, F. and Jörntell, H. (2014). Spatio-temporal skin strain distributions evoke low variability spike responses in cuneate neurons, J. R. Soc. Interface 11, 20131015. DOI:10.1098/rsif.2013.1015.

Hsiao, S. S., Lane, J. and Fitzgerald, P. (2002). Representation of orientation in the somatosensory system, Behav. Brain Res. 135, 93-103.

Huerta, M. F. and Pons, T. P. (1990). Primary motor cortex receives input from area 3a in macaques, Brain Res. 537, 367-371.

Ionta, S., Ferretti, A., Merla, A., Tartaro, A. and Romani, G. L. (2010). Step-by-step: the effects of physical practice on the neural correlates of locomotion imagery revealed by fMRI, Hum. Brain Mapp. 31, 694-702.

Ionta, S., Sforza, A., Funato, M. and Blanke, O. (2013). Anatomically plausible illusory posture affects mental rotation of body parts, Cogn. Affect. Behav. Neurosci. 13, 197-209.

Ionta, S., Martuzzi, R., Salomon, R. and Blanke, O. (2014). The brain network reflecting bodily self-consciousness: a functional connectivity study, Soc. Cogn. Affect. Neurosci. 9, 19041913.

Ionta, S., Villiger, M., Jutzeler, C., Curt, A. and Gassert, R. (2016). Spinal cord injury affects the interplay between visual and sensorimotor representations of the body, Sci. Rep. 6, 20144. DOI:10.1038/srep20144. 
Ishida, H., Fornia, L., Grandi, L. C., Umiltà, M. A. and Gallese, V. (2013). Somato-motor haptic processing in posterior inner perisylvian region $(\mathrm{SII} / \mathrm{pIC})$ of the macaque monkey, PLoS ONE 8, e69931. DOI:10.1371/journal.pone.0069931.

Jang, S. H. (2010). Prediction of motor outcome for hemiparetic stroke patients using diffusion tensor imaging: a review, NeuroRehabilitation 27, 367-372.

Johansson, R. S. and Flanagan, J. R. (2009). Coding and use of tactile signals from the fingertips in object manipulation tasks, Nat. Rev. Neurosci. 10, 345-359.

Johnson, K. O. (2001). The roles and functions of cutaneous mechanoreceptors, Curr. Opin. Neurobiol. 11, 455-461.

Johnson, K. O. and Lamb, G. (1981). Neural mechanisms of spatial tactile discrimination: neural patterns evoked by braille-like dot patterns in the monkey, J. Physiol. 310, 117-144.

Johnson, K. O. and Phillips, J. R. (1988). A rotating drum stimulator for scanning embossed patterns and textures across the skin, J. Neurosci. Meth. 22, 221-231.

Jörntell, H., Bengtsson, F., Geborek, P., Spanne, A., Terekhov, A. V. and Hayward, V. (2014). Segregation of tactile input features in neurons of the cuneate nucleus, Neuron 83, 1444 1452.

Kato, N., Tanaka, T., Sugihara, S. and Shimizu, K. (2015). Development and evaluation of a new telerehabilitation system based on VR technology using multisensory feedback for patients with stroke, J. Phys. Ther. Sci. 27, 3185-3190.

Killebrew, J. H., Bensmaia, S. J., Dammann, J. F., Denchev, P., Hsiao, S. S., Craig, J. C. and Johnson, K. O. (2007). A dense array stimulator to generate arbitrary spatio-temporal tactile stimuli, J. Neurosci. Meth. 161, 62-74.

Kim, E., Sugg, K., Langhals, N., Lightbody, S., Baltrusaitis, M., Urbanchek, M., Cederna, P. and Gerling, G. J. (2013). An engineered tactile afferent modulation platform to elicit compound sensory nerve action potentials in response to force magnitude, in: IEEE World Haptics Conference (WHC), 2013, Daejeon, Korea, pp. 241-246.

Kleim, J. A. and Jones, T. A. (2008). Principles of experience-dependent neural plasticity: implications for rehabilitation after brain damage, J. Speech Lang. Hear. Res. 51, S225-S239.

Klöcker, A., Oddo, C. M., Camboni, D., Penta, M. and Thonnard, J.-L. (2014). Physical factors influencing pleasant touch during passive fingertip stimulation, PLOS ONE 9, e101361. DOI:10.1371/journal.pone.0101361.

Ku, J., Mraz, R., Baker, N., Zakzanis, K. K., Lee, J. H., Kim, I. Y., Kim, S. I. and Graham, S. J. (2003). A data glove with tactile feedback for FMRI of virtual reality experiments, Cyberpsychol. Behav. 6, 497-508.

Kyung, K.-U., Ahn, M., Kwon, D.-S. and Srinivasan, M. A. (2006). A compact planar distributed tactile display and effects of frequency on texture judgment, Adv. Robot. 20, 563580.

LaMotte, R., Whitehouse, G., Robinson, C. and Davis, F. (1983). A tactile stimulator for controlled movements of textured surfaces across the skin, J. Electrophysiol. Techn. 10, 1-17.

Lang, C. E., Wagner, J. M., Edwards, D. F. and Dromerick, A. W. (2007). Upper extremity use in people with hemiparesis in the first few weeks after stroke, J. Neurol. Phys. Ther. 31, 56-63.

Lang, C. E., Macdonald, J. R., Reisman, D. S., Boyd, L., Jacobson Kimberley, T., SchindlerIvens, S. M., Hornby, T. G., Ross, S. A. and Scheets, P. L. (2009). Observation of amounts 
of movement practice provided during stroke rehabilitation, Arch. Phys. Med. Rehabil. 90, 1692-1698.

Le, Q., Qu, Y., Tao, Y. and Zhu, S. (2014). Effects of repetitive transcranial magnetic stimulation on hand function recovery and excitability of the motor cortex after stroke: a meta-analysis, Am. J. Phys. Med. Rehabil. 93, 422-430.

Leergaard, T. B. and Bjaalie, J. G. (2007). Topography of the complete corticopontine projection: from experiments to principal maps, Front. Neurosci. 1, 211-223.

Lefaucheur, J. P., Andre-Obadia, N., Antal, A., Ayache, S. S., Baeken, C., Benninger, D. H., Cantello, R. M., Cincotta, M., de Carvalho, M., De Ridder, D., Devanne, H., Di Lazzaro, V., Filipovic, S. R., Hummel, F. C., Jaaskelainen, S. K., Kimiskidis, V. K., Koch, G., Langguth, B., Nyffeler, T., Oliviero, A., Padberg, F., Poulet, E., Rossi, S., Rossini, P. M., Rothwell, J. C., Schonfeldt-Lecuona, C., Siebner, H. R., Slotema, C. W., Stagg, C. J., Valls-Sole, J., Ziemann, U., Paulus, W. and Garcia-Larrea, L. (2014). Evidence-based guidelines on the therapeutic use of repetitive transcranial magnetic stimulation (rTMS), Clin. Neurophysiol. 125, 2150-2206.

Löken, L. S., Wessberg, J., Morrison, I., McGlone, F. and Olausson, H. (2009). Coding of pleasant touch by unmyelinated afferents in humans, Nat. Neurosci. 12, 547-548.

Looft, F. J. and Williams, W. J. (1979). On-line receptive field mapping of cutaneous receptors, IEEE Trans. Biomed. Eng. 26, 350-356.

Luke, L. M., Allred, R. P. and Jones, T. A. (2004). Unilateral ischemic sensorimotor cortical damage induces contralesional synaptogenesis and enhances skilled reaching with the ipsilateral forelimb in adult male rats, Synapse 54, 187-199.

Lunghi, C. and Morrone, M. C. (2013). Early interaction between vision and touch during binocular rivalry, Multisens. Res. 26, 291-306.

Martuzzi, R., Van der Zwaag, W., Farthouat, J., Gruetter, R. and Blanke, O. (2014). Human finger somatotopy in areas 3b, 1, and 2: a 7T fMRI study using a natural stimulus, Hum. Brain Mapp. 35, 213-226.

Matyas, F., Sreenivasan, V., Marbach, F., Wacongne, C., Barsy, B., Mateo, C., Aronoff, R. and Petersen, C. C. (2010). Motor control by sensory cortex, Science 330, 1240-1243.

McGlone, F., Wessberg, J. and Olausson, H. (2014). Discriminative and affective touch: sensing and feeling, Neuron 82, 737-755.

Meehan, S. K., Randhawa, B., Wessel, B. and Boyd, L. A. (2011). Implicit sequence-specific motor learning after subcortical stroke is associated with increased prefrontal brain activations: an fMRI study, Hum. Brain Mapp. 32, 290-303.

Meyer, K., Kaplan, J. T., Essex, R., Damasio, H. and Damasio, A. (2011). Seeing touch is correlated with content-specific activity in primary somatosensory cortex, Cereb. Cortex $\mathbf{2 1}$, 2113-2121.

Mountcastle, V. B. (1957). Modality and topographic properties of single neurons of cat's somatic sensory cortex, J. Neurophysiol. 20, 408-434.

Murase, N., Duque, J., Mazzocchio, R. and Cohen, L. G. (2004). Influence of interhemispheric interactions on motor function in chronic stroke, Ann. Neurol. 55, 400-409.

Murray, E. A. and Mishkin, M. (1984). Relative contributions of SII and area 5 to tactile discrimination in monkeys, Behav. Brain Res. 11, 67-83.

Nakazawa, N., Ikeura, R. and Inooka, H. (2000). Characteristics of human fingertips in the shearing direction, Biol. Cybern. 82, 207-214. 
Oddo, C. M., Beccai, L., Vitiello, N., Wasling, H. B., Wessberg, J. and Carrozza, M. C. (2011a). A mechatronic platform for human touch studies, Mechatronics 21, 604-613.

Oddo, C. M., Controzzi, M., Beccai, L., Cipriani, C. and Carrozza, M. C. (2011b). Roughness encoding for discrimination of surfaces in artificial active-touch, IEEE Trans. Robot. 27, $522-533$.

Oddo, C. M., Raspopovic, S., Artoni, F., Mazzoni, A., Spigler, G., Petrini, F., Giambattistelli, F., Vecchio, F., Miraglia, F., Zollo, L., Pino, G. D., Camboni, D., Carrozza, M. C., Guglielmelli, E., Rossini, P. M., Faraguna, U. and Micera, S. (2016). Intraneural stimulation elicits discrimination of textural features by artificial fingertip in intact and amputee humans, eLife, DOI: $10.7554 /$ eLife.09148.

Olausson, H., Lamarre, Y., Backlund, H., Morin, C., Wallin, B. G., Starck, G., Ekholm, S., Strigo, I., Worsley, K., Vallbo, A. B. and Bushnell, M. C. (2002). Unmyelinated tactile afferents signal touch and project to insular cortex, Nat. Neurosci. 5, 900-904.

Ortiz-Catalan, M., Håkansson, B. and Brånemark, R. (2014). An osseointegrated humanmachine gateway for long-term sensory feedback and motor control of artificial limbs, Science Transl. Med. 6, 257re256. DOI:10.1126/scitranslmed.3008933.

Pawluk, D. T. and Howe, R. D. (1999). Dynamic lumped element response of the human fingerpad, J. Biomech. Eng. 121, 178-183.

Penfield, W. and Boldrey, E. (1937). Somatic motor and sensory representation in the cerebral cortex of man as studied by electrical stimulation, Brain 60, 389-443.

Perruchoud, D., Murray, M. M., Lefebvre, J. and Ionta, S. (2014). Focal dystonia and the sensory-motor integrative loop for enacting (SMILE), Front. Hum. Neurosci. 8, 458. DOI:10.3389/fnhum.2014.00458.

Picard, N. and Smith, A. (1992). Primary motor cortical activity related to the weight and texture of grasped objects in the monkey, J. Neurophysiol. 68, 1867-1881.

Pihko, E., Nangini, C., Jousmäki, V. and Hari, R. (2010). Observing touch activates human primary somatosensory cortex, Eur. J. Neurosci. 31, 1836-1843.

Pisotta, I., Perruchoud, D. and Ionta, S. (2015). Hand-in-hand advances in biomedical engineering and sensorimotor restoration, J. Neurosci. Meth. 246, 22-29.

Pohl, P. S. and Winstein, C. J. (1999). Practice effects on the less-affected upper extremity after stroke, Arch. Phys. Med. Rehabil. 80, 668-675.

Qiu, M., Darling, W. G., Morecraft, R. J., Ni, C. C., Rajendra, J. and Butler, A. J. (2011). White matter integrity is a stronger predictor of motor function than BOLD response in patients with stroke, Neurorehabil. Neural Repair 25, 275-284.

Rasmussen, T. and Penfield, W. (1947). The human sensorimotor cortex as studied by electrical stimulation, Fed. Proc. 6, 184.

Raspopovic, S., Capogrosso, M., Petrini, F. M., Bonizzato, M., Rigosa, J., Di Pino, G., Carpaneto, J., Controzzi, M., Boretius, T., Fernandez, E., Granata, G., Oddo, C. M., Citi, L., Ciancio, A. L., Cipriani, C., Carrozza, M. C., Jensen, W., Guglielmelli, E., Stieglitz, T., Rossini, P. M. and Micera, S. (2014). Restoring natural sensory feedback in real-time bidirectional hand prostheses, Science Transl. Med. 6, 222ra219. DOI:10.1126/scitranslmed.3006820.

Rizzolatti, G., Fogassi, L. and Gallese, V. (2002). Motor and cognitive functions of the ventral premotor cortex, Curr. Opin. Neurobiol. 12, 149-154. 
Romo, R., Ruiz, S., Crespo, P. and Hsiao, S. S. (1993). A tactile stimulator for studying motion processing in the somatic sensory system of primates, J. Neurosci. Meth. 46, 139-146.

Romo, R., Hernández, A., Zainos, A., Brody, C. and Salinas, E. (2002a). Exploring the cortical evidence of a sensory-discrimination process, Philos. Trans. R. Soc. Lond. B Biol. Sci. 357, 1039-1051.

Romo, R., Hernández, A., Zainos, A., Lemus, L. and Brody, C. D. (2002b). Neuronal correlates of decision-making in secondary somatosensory cortex, Nat. Neurosci. 5, 1217-1225.

Rongala, U. B., Mazzoni, A., Camboni, D., Carrozza, M. C. and Oddo, C. M. (2015). Neuromorphic artificial sense of touch: bridging robotics and neuroscience, in: International Symposium on Robotics Research, A. Bicchi Worg (Ed.), pp. 1-14. Sestri Levante, Italy.

Rossetti, A., Miniussi, C., Maravita, A. and Bolognini, N. (2012). Visual perception of bodily interactions in the primary somatosensory cortex, Eur. J. Neurosci. 36, 2317-2323.

Rothwell, J. C., Traub, M. M., Day, B. L., Obeso, J. A., Thomas, P. K. and Marsden, C. D. (1982). Manual motor performance in a deafferented man, Brain 105, 515-542.

Ruben, J., Schwiemann, J., Deuchert, M., Meyer, R., Krause, T., Curio, G., Villringer, K., Kurth, R. and Villringer, A. (2001). Somatotopic organization of human secondary somatosensory cortex, Cereb. Cortex 11, 463-473.

Saal, H. P. and Bensmaia, S. J. (2015). Biomimetic approaches to bionic touch through a peripheral nerve interface, Neuropsychologia 79B, 344-353.

Sanchez-Panchuelo, R. M., Francis, S., Bowtell, R. and Schluppeck, D. (2010). Mapping human somatosensory cortex in individual subjects with 7T functional MRI, J. Neurophysiol. 103, 2544-2556.

Sanchez-Panchuelo, R. M., Besle, J., Beckett, A., Bowtell, R., Schluppeck, D. and Francis, S. (2012). Within-digit functional parcellation of Brodmann areas of the human primary somatosensory cortex using functional magnetic resonance imaging at 7 Tesla, J. Neurosci. 32, 15815-15822.

Sanger, T. D. and Merzenich, M. M. (2000). Computational model of the role of sensory disorganization in focal task-specific dystonia, J. Neurophysiol. 84, 2458-2464.

Sawaki, L., Butler, A. J., Xiaoyan, L., Wassenaar, P. A., Mohammad, Y. M., Blanton, S., Sathian, K., Nichols-Larsen, D. S., Wolf, S. L., Good, D. C. and Wittenberg, G. F. (2008). Constraintinduced movement therapy results in increased motor map area in subjects 3 to 9 months after stroke, Neurorehabil. Neural Repair 22, 505-513.

Schaechter, J. D., Moore, C. I., Connell, B. D., Rosen, B. R. and Dijkhuizen, R. M. (2006). Structural and functional plasticity in the somatosensory cortex of chronic stroke patients, Brain 129, 2722-2733.

Schaechter, J. D., Fricker, Z. P., Perdue, K. L., Helmer, K. G., Vangel, M. G., Greve, D. N. and Makris, N. (2009). Microstructural status of ipsilesional and contralesional corticospinal tract correlates with motor skill in chronic stroke patients, Hum. Brain Mapp. 30, 34613474.

Schaefer, M., Xu, B., Flor, H. and Cohen, L. G. (2009). Effects of different viewing perspectives on somatosensory activations during observation of touch, Hum. Brain Mapp. 30, 27222730.

Scheibert, J., Leurent, S., Prevost, A. and Debrégeas, G. (2009). The role of fingerprints in the coding of tactile information probed with a biomimetic sensor, Science 323, 1503-1506. 
Schlerf, J., Ivry, R. B. and Diedrichsen, J. (2012). Encoding of sensory prediction errors in the human cerebellum, J. Neurosci. 32, 4913-4922.

Scholz, J., Klein, M. C., Behrens, T. E. and Johansen-Berg, H. (2009). Training induces changes in white-matter architecture, Nat. Neurosci. 12, 1370-1371.

Shadmehr, R. and Krakauer, J. W. (2008). A computational neuroanatomy for motor control, Exp. Brain Res. 185, 359-381.

Shimizu, E., Hashimoto, K. and Iyo, M. (2004). Major depressive disorders and BDNF (brainderived neurotrophic factor), Jpn. J. Psychopharmacol. 24, 147-150.

Simões-Franklin, C., Whitaker, T. A. and Newell, F. N. (2011). Active and passive touch differentially activate somatosensory cortex in texture perception, Hum. Brain Mapp. 32, 1067-1080.

Sinclair, R. J. and Burton, H. (1993). Neuronal activity in the second somatosensory cortex of monkeys (Macaca mulatta) during active touch of gratings, J. Neurophysiol. 70, 331-350.

Sporns, O., Chialvo, D. R., Kaiser, M. and Hilgetag, C. C. (2004). Organization, development and function of complex brain networks, Trends Cogn. Sci. 8, 418-425.

Stinear, C. M., Barber, P. A., Smale, P. R., Coxon, J. P., Fleming, M. K. and Byblow, W. D. (2007). Functional potential in chronic stroke patients depends on corticospinal tract integrity, Brain 130, 170-180.

Stinear, C. M., Barber, P. A., Petoe, M., Anwar, S. and Byblow, W. D. (2012). The PREP algorithm predicts potential for upper limb recovery after stroke, Brain 135, 2527-2535.

Stringer, E. A., Chen, L. M., Friedman, R. M., Gatenby, C. and Gore, J. C. (2011). Differentiation of somatosensory cortices by high-resolution fMRI at 7 T, Neuroimage 54, 1012-1020.

Stys, P. K. and Lipton, S. A. (2008). White matter NMDA receptors: an unexpected new therapeutic target? Trends Pharmacol. Sci. 28, 561-566.

Summers, I. R. and Chanter, C. M. (2002). A broadband tactile array on the fingertip, J. Acoust. Soc. Am. 112, 2118-2126.

Sun, H., Blakely, T. M., Darvas, F., Wander, J. D., Johnson, L. A., Su, D. K., Miller, K. J., Fetz, E. E. and Ojemann, J. G. (2015). Sequential activation of premotor, primary somatosensory and primary motor areas in humans during cued finger movements, Clin. Neurophysiol. 11, 2150-2161.

Tamburin, S., Manganotti, P., Zanette, G. and Fiaschi, A. (2001). Cutaneomotor integration in human hand motor areas: somatotopic effect and interaction of afferents, Exp. Brain Res. 141, 232-241.

Tan, D. W., Schiefer, M. A., Keith, M. W., Anderson, J. R., Tyler, J. and Tyler, D. J. (2014). A neural interface provides long-term stable natural touch perception, Science Transl. Med. 6, 257ra138. DOI:10.1126/scitranslmed.3008669.

Tanaka, K., Nogawa, S., Suzuki, S., Dembo, T. and Kosakai, A. (2003). Upregulation of oligodendrocyte progenitor cells associated with restoration of mature oligodendrocytes and myelination in peri-infarct area in the rat brain, Brain Res. 989, 172-179.

Tanji, J., Shima, K. and Mushiake, H. (1996). Multiple cortical motor areas and temporal sequencing of movements, Cogn. Brain Res. 5, 117-122.

Taub, E., Miller, N. E., Novack, T. A., Cook, E. W., Fleming, W. C., Nepomuceno, C. S., Connell, J. S. and Crago, J. E. (1993). Technique to improve chronic motor deficit after stroke, Arch. Phys. Med. Rehabil. 74, 347-354. 
Thakur, P. H., Fitzgerald, P. J., Lane, J. W. and Hsiao, S. S. (2006). Receptive field properties of the macaque second somatosensory cortex: nonlinear mechanisms underlying the representation of orientation within a finger pad, J. Neurosci. 26, 13567-13575.

Tinga, A. M., Visser-Meily, J. M. A., Van der Smagt, M. J., Van der Stigchel, S., Van Ee, R. and Nijboer, T. C. W. (2016). Multisensory stimulation to improve low-and higher-level sensory deficits after stroke: a systematic review, Neuropsychol. Rev. 26, 73-91.

Tomassini, A., Gori, M., Burr, D., Sandini, G. and Morrone, M. C. (2011). Perceived duration of visual and tactile stimuli depends on perceived speed, Front. Integr. Neurosci. 5, 51. DOI:10.3389/fnint.2011.00051.

Tononi, G. and Cirelli, C. (2014). Sleep and the price of plasticity: from synaptic and cellular homeostasis to memory consolidation and integration, Neuron 81, 12-34.

Vallbo, A., Olausson, H., Wessberg, J. and Norrsell, U. (1993). A system of unmyelinated afferents for innocuous mechanoreception in the human skin, Brain Res. 628, 301-304.

Vallbo, A. B., Olausson, H., Wessberg, J. and Kakuda, N. (1995). Receptive field characteristics of tactile units with myelinated afferents in hairy skin of human subjects, J. Physiol. 483, 783-795.

Van den Brink, R. L., Cohen, M. X., Van der Burg, E., Talsma, D., Vissers, M. E. and Slagter, H. A. (2014). Subcortical, modality-specific pathways contribute to multisensory processing in humans, Cereb. Cortex 24, 2169-2177.

Van der Knaap, M. and Valk, J. (2005). Magnetic Resonance of Myelination and Myelin Disorders, 3rd edn. Springer, Berlin, Germany.

Velicki, M. R., Winstein, C. J. and Pohl, P. S. (2000). Impaired direction and extent specification of aimed arm movements in humans with stroke-related brain damage, Exp. Brain Res. 130, 362-374.

Vidal-Verdú, F. and Hafez, M. (2007). Graphical tactile displays for visually-impaired people, IEEE Trans. Neural Syst. Rehabil. Eng. 15, 119-130.

Vidoni, E. D. and Boyd, L. A. (2009). Preserved motor learning after stroke is related to the degree of proprioceptive deficit, Behav. Brain Funct. 5, 36. DOI:10.1186/1744-9081-5-36.

Von Holst, E. and Mittelstaedt, H. (1950). Das reafferenz Princip: (Wechlselwirkungen zwischen Zentrainervensystem und Peripherie), Naturwissenschaften 37, 464-476.

Weber, A. I., Saal, H. P., Lieber, J. D., Cheng, J.-W., Manfredi, L. R., Dammann, J. F. and Bensmaia, S. J. (2013). Spatial and temporal codes mediate the tactile perception of natural textures, Proc. Natl Acad. Sci. USA 110, 17107-17112.

Weinstein, S. (1968). Intensive and extensive aspects of tactile sensitivity as a function of body part, sex and laterality, in: The Skin Senses, D. Kenshalo (Ed.), pp. 192-222. Charles C. Thomas, Springfield, IL, USA.

Weiskrantz, L., Elliot, J. and Darlington, C. (1971). Preliminary observations on tickling oneself, Nature 230(5296), 598-599.

Werring, D. J., Toosy, A. T., Clark, C. A., Parker, G. J., Barker, G. J., Miller, D. H. and Thompson, A. J. (2000). Diffusion tensor imaging can detect and quantify corticospinal tract degeneration after stroke, J. Neurol. Neurosurg. Psychiatry 69, 269-272.

Wheat, H. E., Salo, L. M. and Goodwin, A. W. (2004). Human ability to scale and discriminate forces typical of those occurring during grasp and manipulation, J. Neurosci. 24, 33943401 . 
Wiertlewski, M., Lozada, J. and Hayward, V. (2011). The spatial spectrum of tangential skin displacement can encode tactual texture, IEEE Trans. Robot. 27, 461-472.

Winstein, C. J., Merians, A. S. and Sullivan, K. J. (1999). Motor learning after unilateral brain damage, Neuropsychologia 37, 975-987.

Wolpert, D. M., Ghahramani, Z. and Jordan, M. I. (1995). An internal model for sensorimotor integration, Science 269, 1880-1882.

Wolpert, D. M., Goodbody, S. J. and Husain, M. (1998). Maintaining internal representations: the role of the human superior parietal lobe, Nat. Neurosci. 1, 529-533.

Wolpert, D. M., Miall, R. C. and Kawato, M. (1998). Internal models in the cerebellum, Trends Cogn. Sci. 2, 338-347. 